\title{
ФІЛОСОФІЯ
}

УДК 141.7: [316.61+316.7]

DOI https://doi.org/10.32837/apfs.v0i26.898

\author{
Е. А. Белякова \\ ORCID ID: 0000-0002-4636-1157 \\ аспирант кафедры соииальной философии и управления \\ Запорожского национального университета
}

\section{ДЕКОНСТРУКЦИЯ БИНАРНОЙ ОППОЗИЦИИ КАТЕГОРИЙ ЧЕЛОВЕКА И КУЛЬТУРЫ КАК ЗАКЛЮЧИТЕЛЬНЫЙ ЭТАП ИХ ПОСТНЕКЛАССИЧЕСКОЙ КОНЦЕПТУАЛИЗАЦИИ}

Постановка проблемы. Первый этап концептуализации феноменов человека и культуры, результаты которого были изложены нами в предыдущих статьях, позволяет предварительно осмыслить указанные феномены в их эмпирической данности. Завершенный же концепт должен представить концептуализируемое явление в динамике необходимости его исторического развертывания.

В наших предыдущих статьях, говоря о человеке и культуре, мы были вынуждены в процессе предварительной социально-философской концептуализации указанных феноменов упоминать о социальной отрасли культуры и социальном человеке. Поскольку человек и культура являются моментами антропосоциокультурной тотальности, их концептуализация не представляется завершенной, если этот процесс не доведен до концептуализации феномена социальности.

Целью статьи является завершение постнеклассической социально-философской концептуализации человека и культуры.

Изложение основного материала. $K$ проблеме концептуализации человека и культуры обращались многие исследователи, разработавшие отдельные аспекты этой многогранной темы. Холистический подход к такому роду концептуализации был предложен еще в работах сначала Сорокина П.А. [19], затем Кагана М.С. - антропосоциокультурный подход [5]. Кизима предложил понятие тотальности [6], Манжура В.И. - концепт антропосоциокультурной тотальности [8; 9]. Саитгареева О.Г. предложила концепт социетального типа личности, идущего на смену экономического человеку [17]. Цупренко 3.В. исследовала связь между возрастанием человечности и жизнеспособностью человеческих сообществ [21]. В статьях Беляковой Е.А. предложены принципы концептуализации способом деконструкции категорий человека и культуры [1-3].

Опираясь на предыдущие исследования, мы можем утверждать, что антропогенез и культуро- генез зарождаются в природе одновременно, поскольку «видовой» человек, культивируя в себе свои родовые качества, ведущим среди которых является креативность, изменяет объем родового развития, соответственно, что равносильно изменению также и объема культурного развития.

Культура в своей действительности как социоантропный феномен существует не иначе как в виде интериоризированной культурным сообществом массы актуальных культурных компетенций, необходимых для его выживания. Актуальными компетенциями или актуальной частью наличного объема культурного (родового) развития мы называем те из них, которые являются значимым для жизнеспособности общества в текущий момент его истории и в наличной природной среде. Поэтому значимые достижения человека-креатора так или иначе необходимо должны быть опредмечены в артефактах материальной культуры, т.к. трансляция накопленного родового развития осуществляется путем распредмечивания опредмеченных человеческих сущностных сил, каковые заключаются в культивированных знаниях, умениях и навыках. На заре человеческой истории творцам важно было передать актуальные культурные компетенции новому поколению в пространстве, то есть в процессе непосредственного общения, с развитием же письменности и иного рода знаковых систем появилась возможность сохранять и в дальнейшем транслировать их и во врелени посредством письменных культурных памятников, отображающих алгоритмы, механизмы, техники и технологии того или иного ремесла, производственного процесса и т.д.

В отличие от видового генотипа, несущего в себе всю биологическую историю, родовой генотип человеком не наследуется, поэтому следует согласиться с Дж. Локком, что психика новорожденного - не что иное, как tabula rasa. Различие между этими генетическими программами заключается в том, что перевозникновение каждой 
новой особи в процессе воспроизводства видовой жизни происходит как бы «автоматически», без участия самой особи, тогда как родовой онтогенез требует усилий предыдущего поколения по транслированию необходимых компетенций, а также усилий нового поколения по «распредмечиванию» накопленного объема родового, социокультурного развития.

То есть, чтобы стать представителем рода человеческого необходимо освоить некую часть накопленного объёма предыдущими поколениями культурного развития в виде индивидуальной социокультурной компетенции. На заре зарождения человечества накопленный объем культурного развития был настолько незначителен, что позволял любому члену первобытного сообщества (как мужчине, так и женщине) освоить его полностью.

Однако, на протяжении всего исторического процесса объем культурного развития неуклонно, хотя и с разной скоростью, разными темпами - возрастет, причем темпы культурного развития прямо пропорциональны глубине разделения труда и фрагментации наличного объема культурного развития, распределяемого между членами первобытного общества. Накопленный современным человечеством объем культурного генотипа в полной мере никто из них освоить уже не в состоянии, будучи, тем не менее, погруженным в культурную среду, созданную всеми предшествующими поколениями.

C возникновением общественного производства, кроме природного отношение к среде и внутрипопуляционных видовых отношений, известных уже животному миру, среди людей необходимо возникают «протосоциальные» отношения «3 приводу виробництва, розподілу, і споживання матеріальних умов родового життя» [2, с. 24]. Начало же фрагментации и распределение накопленного объема культурного развития обратной своей стороной было возникновением собственно социальности как атрибута собственно человека [подробнее см. статья о культ]. Разделение труда стало первой в истории человека социокультурной инновацией, которая привела к первичной специализации, вследствие чего у мужских и женских особей этого бисексуального вида возникла потребность друг в друге не только как в существах противоположного пола, но и как в носителях недостающих для необходимой полноты фрагментов актуальных культурных компетенций. Видовые стадные существа стали родовыми социальными, т.е. социокультурными существами, а антропокультурогенез перерос в антропосоциокультурогенез [подробнее см. 2]. И превращение «истории первобытной орды», в «действительную историю развития общества», случается раньше, чем, - как это иногда представляется - «развитие производительных сил делает возможной выработку избыточного продукта»
[10, с. 371]. При всем различии компетенций первобытных «профессионалов» их носители оставались равными между собой по признаку целостности и всеохватности их культурнопрофессиональных компетенций, включавших в себя и первичную, и вторичную креативность, а также исполнительскую культуру. Закрепление каждого члена первобытного сообщества за определенной областью деятельности вела к развитию рабочей силы как момента эволюции антропной культуры. Постепенная профессионализация, в свою очередь, вела к повышению производительности труда, социоантропный эффект от разделения труда предшествовал социокультурному.

Важными социоантропными следствиями этой инновации было повышение вероятности полезных наблюдений и случайных удачных манипуляций, приводивших к созданию более эффективных орудий и технологий, повышающих производительность труда и увеличения массы свободного времени, которое первоначально делится между всеми членами первобытного сообщества, и используется ими для создания неутилитарных предметов - в т. ч. и произведений первобытного искусства.

Социокультурные эффекты данной инновации проявились в возрастании массы свободного времени, что в свою очередь вело к появлению и возрастанию возможности резкого ускорения темпов культурного развития при другом способе его распределения и потребления. Необходимость же в такого рода ускорении возникает либо в периоды резкого изменения значимых характеристик окружающей среды, усиливающих ее давление на локальные человеческие популяции, либо же в периоды увеличения численности человеческих популяций, усиливающих давление популяции на экосистему данного ареала.

Конструируя концептуальную модель процесса изменения типов социальности человека и культуры, мы рассматриваем процесс перехода от первичной эпохи с характерными для нее социальными отношениями равенства, сотрудничества и взаимопомощи к вторичной эпохе с присущими ей отношениями неравенства, эксплуатации и угнетения, выразившимися в отнимании у непосредственного производителя произведенного им прибавочного продукта и опредмеченного в этом последнем свободного времени.

Диалектическое соотношение между животным и человеческим, видовым и родовым в возникающем человеке, готовым и искусственным, присвоенным и преобразованным природным ресурсом, равенством и неравенством в отношениях между людьми меняется медленно, но неизменно. Переход от охоты к скотоводству и от собирательства к земледелию произошел в рамках первобытной общины, которая еще сохранила равенство. Возобладание 
искусственного над присвоенным является скачком в иную социальность, а отнимание прибавочного продукта без нанесения ущерба жизнедеятельности раба является второй важнейшей социальной инновацией. Парадоксально, но биологическая эволюция человека, протекавшая быстрее культурной, на данном этапе замедлилась, в то время как культурная или, точнее говоря, - культурно-социальная эволюция набирает обороты.

Если тип личности, доминирующей в первобытном обществе - это коммунитарный человек, живущий в условиях вынужденного равенства, то с приходом цивилизации новый исторический тип личности можно назвать экономическим человеком, отнимающим прибавочное время у угнетенных им масс и устанавливающим, таким образом классическую форму рабства.

Следствием такого отнимания и, следовательно, накапливания свободных человеко-часов, явилось отделение в эпоху античности умственного труда от физического, материального производства от духовного. Такое разделение труда и фрагментирование наличного объема родового развития будет уже не столько профессиональным, сколько социальным. Теперь свободное время концентрируется в руках меньшинства и господствующий класс использует его по своему усмотрению. Чтобы держать рабов в повиновении они создают государство, политику, законодательство, репрессивные органы и т. д. Хотя эффективность использования свободного времени античными аристократами была очень далека от оптимальной с точки зрения его влияния на темпы культурного развития, эти последние ускорились минимум в сотни раз - (2-4\% за 100 лет против 1-2\% за 10 тыс. лет в первобытную эпоху) [20, с. 282-284].

Распорядители свободного временем могли стать профессиональными производителями новых знаний (учеными) и эстетических ценностей (художниками, писателями, архитекторами), философами, государственными деятелями и т.д.). Но, одновременно быть развитыми и человечным в эту эпоху было невозможно, примером чему является Аристотель, который, осознавая, что его развитость базируется на бесчеловечной эксплуатации рабов, успокаивал свою больную совесть, утверждая, что раб - не более чем «говорящее орудие». Но Аристотель, в отличие от многих других потребителей свободного времени аристократов, относится к той их части, которые своими культурными усилиями во благо человечества оправдали эту свою вынужденную бесчеловечность.

Несложно проследить прямую зависимость между тем, сколько произведут угнетенные люди сверх необходимого продукта и тем, сколько свободных людей при желании могут развиться за их счет.

Человечность при этом, как ни парадоксально, продолжает возрастать как результат своев- ременно принятых экономически и социально выгодных решений. Примером такого решения может служить политика Солона, чьи реформы «утвердили социальность, детерминированную разумом и человечностью» [4, с. 115]. Осознавая нарастающий кризис Афин и обострение противостояния между рабами и их господами, Солон отменил долговое рабство и тем самым, если говорить высоким слогом, - закрепил, таким образом, «за свободой качество неотчуждаемого права личности афинянина» [4, с. 116], хотя на самом деле он понял опасность уменьшения доли свободных граждан при сохранении института долгового рабства и размывания тем самым социальной базы государственной власти. Римские императоры заботились о том же, организуя бесплатное питание и развлечения для неимущей части граждан Рима.

Скачок от рабовладельческого строя к феодальному произошел вследствие того, Римская империя, изначально завоевав варварские территории в дальнейшем культурно развила их до той степени, при которой завоеванные, усвоив основные достижения хозяйственной и военной культуры завоевателя, перестали быть его легкой добычей и на смену рабовладельческой знати пришла выросшая из первобытной военной демократии феодальная знать, которая, владея земельными угодьями и предоставляя своим крестьян вооруженную защиту от вооруженных рыцарских формирований делает «упор ... на профессиональное воинское формирование, во главе которого стоял наследственный воин-рыцарь» [15, с. 16]. Экономическое превосходство феодализма над рабовладением заключалось прежде всего в том, что себестоимость воспроизводства рабочей силы в семье крестьянина оказывается ниже, чем стоимость раба на невольничьем рынке, вольноотпущенник, получивший надел земли и обязанный платить своему вчерашнему хозяину фиксированный оброк, в отличие от раба, реально заинтересован в производительном труде. Более того, «крестьяне были профессиональными наследственными земледельцами, а значит, эффективность их работы на земле была выше, чем у полупрофессиональных рабов», которые к тому же не были замотивированы в труде [15, с. 16]. Феодальный тип социальности существует до тех пор, пока остается возможным единство противоположностей «собственник» - «труженик» в данной исторической форме. Напомним, «противоположности через момент взаимопревращения и взаимоотождествления друг с другом, превращаются в единство других противоположностей, т.е. качественно иное явление...» $[1$, с. 26$]$. В ходе национализации земли вчерашний крепостной крестьянин - неимущий труженик, оставаясь тружеником, становится собственником, а вчерашний собственник, которому выделяют из его бывших владений 
причитающуюся ему марку, он, лишенный дармовой рабочей силы, будет вынужден (в идеале), оставаясь собственником стать тружеником. Зарождение буржуазных отношений, скажем, в Англии, было связано с промышленной революцией (в первую очередь, изобретение паровой машины и ткацкого станка), которая повысила спрос на овечью шерсть, и лендлордам стало сложно сбывать выращенные их крестьянами продуты земледелия, а овцеводство становилось весьма прибыльным занятием. Под предлогом дарования личной свободы зависимым крестьянам, феодал сгонял их со своей земли, вынуждая их податься в работные дома и ткацкие фабрики, нуждавшиеся в дешевой рабочей силе. Постепенно развилось новое противоречие социальных отношений и их новая мера - мера капитализма. Тем не менее, руководствуясь исключительно мотивами личной экономической выгоды господствующий класс вновь проявил вынужденную человечность по отношению к классу угнетенных - дал им свободу и впервые в истории человечества обязательное образование - умные «машины ... не требующие длительного периода обучения человека-оператора для управления этим процессом» [15, с. 22-23].

Таким образом, вопрос об извечном противостоянии добра и зла, также разрешается диалектическим способом, т.к. вынужденная бесчеловечность является предпосылкой развития человечности, а именно - создавая новые культурные ценности, производя новые знания, изобретая более эффективные орудия труда и технологии, креаторы повышают уровень культуры и, тем самым, уменьшают масштаб вынужденного зла, с которым добро в эту эпоху неразлучно [21].

Рассмотренные выше такие социальные инновации как разделение труда и отнимание свободного времени очевидно являются социальными артефактами или фактами социальной отрасли культурного производства. Изобретенный первобытными людьми рабовладельческий уклад общественной жизни при всей его жестокости был еще одним шагом по направлению к повышению уровня вынужденной человечности господствующего типа человеческой личности и парадоксальность этого момента человеческой истории хорошо выразил Ф. Энгельс, заметивший в своем «АнтиДюринге», что без античного рабства не было бы современного социализма.

Разделение труда одновременно является и фрагментацией культуры и фрагментацией исторически развитых человеческих сущностных сил, a, следовательно, также фрагментацией родового человека и человеческого сообщества. Каждый член общества по отдельности уже не обладает всеобъемлющим набором актуальных для выживания компетенций, тогда как лишь все вместе они располагают этим объемом человеческих сущностных сил, поэтому отдельно взятый социальный индивид вне культурного сообщества невозможен.

По мере неуклонно углубляющегося разделения труда люди становятся носителями все меньших частей все большего объема культурных достижений, становясь при этом все более и более узкими специалистами. Означает ли это, что человек будет «мельчать» в культурном смысле? Да, это, к сожалению, так, потому что в структуре транслируемых и воспроизводимых родовых сущностных сил человека помимо профессионально-горизонтальной в их системе есть и вертикальное измерение, своего рода слоистая структура культуры. Самый глубинный ее слой образует первичная креaтивность, под которой подразумевается (называемая еще гениальностью) способность генерировать инновативные идеи, и принципиально новые подходы к решению актуальных проблем. Поэтому наличие развитого инновативного мышления у части культурных сообществ является важнейшей гарантией их жизнеспособности. Миссия первичных креаторов заключается «в продуцировании универсально-культурной ценности» [13, с. 180]. Средний слой образует вторичная креативность, «запускаемая» достижениями «первичных» креаторов - она характерна для инженеров, технологов и т.д. Третьим периферийным слоем человеческих сущностных сил является исполнительская культура, носителей которой называют профессионалами или мастерами своего дела.

Если на первобытном этапе каждая индивидуальная культурная компетенция включала в себя все три слоя, то на этапе цивилизации эти профессиональные компетенции "расслоились» и люди как социокультурные существа теперь стали не только более разными, но и неравными друг другу. Цивилизованные же люди разделились на тех, кто производит инновационные идеи, на тех, кто эти идеи воплощает в новую (в том числе в образовательную, управленческую, социальную и т. д.) технику и технологию и тех, кто приводит в действие созданные первыми и вторыми технико-технологические системы.

Переход к культурному способу присутствия в природе меняет законы популяционной биологии человека. Закон естественного отбора продолжает действовать, но его действие модифицировано культурными факторами, и он становится естественноисторическим отбором. Главным фактором естественноисторического отбора, который делит общества на жизнеспособные и нежизнеспособные, является не роскошь и не комфорт их образа жизни и не их военная мощь, а прежде всего их образование и культура, способные культивировать творцов, способных в любой кризисной ситуации создать достаточный объем актуальных культурных инноваций.

На сегодняшний день количества людей первого уровня креативности, которые бы направили 
творческие и умственные усилия на разработку решений вставших перед человечеством актуальных проблем, явно недостаточно, и можно уверенно заявить о креативной, заодно и культурной стагнации, угрожающей существованию современной цивилизации. Неоправданно большая масса свободного времени, высвобожденного трудом одних представителей рода человеческого, бездарно тратится другими на достижение целей, никак не связанных с решением актуальных проблем человечества. Концентрация гениев в культурном сообществе напрямую зависит от объема свободного времени и общественно необходимых его затрат (в человеко-часах) на культивирование одной первичной человеческой креативности, и в конечном счете, от способа распределения, и канализации и потребления свободного времени.

Существенным моментом связи между человеком и культурой является т.н. первичная инкультурация, начальный этап процесса интериоризации человеком необходимых культурных компетенций, обеспечивающих его становление в качестве полноценного социального индивида, называемьй первичной инкультурацией [18].

Если первичная инкультурация первобытного, античного, средневекового человека и даже человека эпохи промышленной революции снабжала его набором знаний, умений и навыков, обеспечивающих его занятость и востребованность на протяжении всей его жизни. В современную же эпоху возрастание темпов обновления поколений техники и технологии приводит к тому, что, в конце концов «время жизни людей теперь больше, чем время смены поколений техники» [11, с. 78], и поэтому для того, чтобы быть востребованным на протяжении всей своей трудовой жизни, человек вынужденно должен пребывать в режиме вторичной креативности, наиболее эффективной формой которой является пожизненное образование.

Подчеркнем, что образование является едва ли не основным социокультурным институтом, целенаправленно формирующим и распределяющим культурогенеративный потенциал общества, и способным активно содействовать конструктивному включению человека в социокультурную ситуацию и полномасштабной реализации его родовых сущностных сил в интересах человеческого рода. Трудно не согласиться с тем, что образование «выступает медиатором между отдельной личностью и культурой в целом (всеми ее кодами), играя исключительную роль в процессах опредмечивания и распредмечивания надындивидуального социокультурного опыта» [22, с. 95]. Образовательные технологии, непрерывно развиваясь и совершенствуясь, способны содействовать повышению темпов развития антропогенеративных (человекопорождающих) технологий за счет снижения затрат свободного времени на производство единицы первичной креативности, культурного являются существенными для развития антропной культуры. А это приближает то время, когда станет возможным непрерывный прирост объема креативности в каждом человеке и на протяжении всей его жизни в постепенно утверждающихся практиках пожизненного образования. Образование должно стать механизмом интериоризации не просто актуальной, а сверх-актуальной культуры в каждое человеческое существо. Образовательный процесс является одной из важнейших культурных практик, работающих на будущее.

Согласно, исследованиям Римского клуба, одной из проблем недалекого будущего станет уменьшение расходов на образование и воспитание детей вследствие замедления роста численности населения и заботы о многочисленных пенсионерах [7]. Такие прогнозы свидетельствуют об устаревшем типе социальности современного общества. Ученые выделяют следующие причины грядущих проблем: «легитимность этоса материального эгоизма» [12, с. 127], «фундаментальный философский кризис общества в настоящей фазе» [12, с. 128], капитализм, как таковой [12, с. 134]; «криза політичних партій i нездатність сучасних інститутів влади управляти світом; втрата ідеологічних цінностей і вакуум, що запанував після розвалу комуністичної системи і фіаско «американської мрії» [16, с. 128]; глобализация, невыполнение корпорациями своих социальных обязательств [14, с. 57]. Причина мирового катаклизма кроется в том, что культура, созданная человечеством, противоестественна для остальной природы, т.е. угрожает «первой» природе ее деградацией, склонной стать необратимой. Подлинно культурной и человечной современную цивилизацию назвать сложно с ее культурой насилия, доминирования, сверхконсьюмеризма, а также «неоварварства». Оказалось, что наличие высоких технологий вовсе не является фактором, определяющим масштаб человечности в обществе. Это может породить вместо культурорегенеративного культуродегенеративный эффект.

Без сомнения, уровень развития культуры и уровень развития человека - взаимосвязаны, т.к. человек - есть тем, кем есть, благодаря тому и в силу того, носителем какой культурной компетенции в количественном и качественном смысле он является. Вэтом его главное социальное различиес другими людьми, производное от социетальной отрасли культуры и социальных отношений, в которых производятся, распределяются и потребляются не только еда, жилье, одежда, но и человеческие сущностные силы. Данный процесс протекает отнюдь не стихийно, а упорядоченным образом, регулируется распределение накопленного объема человеческих родовых сущностных сил при помощи набора на те или иные специальности в соответствии с социальным 
и государственным заказом. Производство и воспроизводство людей и культуры обеспечивается сохранением пропорций, в которых распределяются те или иные конкретные культурные компетенции. K примеру, система каст в Индии является на самом деле способом фиксации известных пропорций профессионального распределения, обоснованным «задним числом» религиозными догмами. Запрет перехода из одной касты в другую обусловлен потенциальной угрозой нарушения пропорции людей занятых теми или иными видами деятельности. Это - не что иное, как сохранение социальной формы процесса антропокультурогенеза, т.е. типа социальности. Следовательно, как преждевременное внедрение того или иного типа социальности, так и долгое его «замораживание» может оказаться губительным для сообщества.

Актуальный тип социальности, таким образом, необходимо следует из уровня развития человека и культуры, а не предшествует ему, хотя и способен ускорять или замедлять темпы развития и того, и другого. Отнимание свободного времени, как вторичная социальная инновация, делит людей на развитых и неразвитых, на тех, кому развитие обеспечено и тех, за чей счет оно обеспечивается, в результате чего наблюдается резкое ускорение культурного развития.

Имея в своем распоряжении достаточное количество свободных человеко-часов, чтобы не быть задействованным в области материального производства, человеку предоставляется возможность реализовать себя полномасштабно, стремясь к тому, чтобы стать личностью, креатором. Материальная отрасль культуры, следовательно, определяет, когда один тип личности уступит место другому в качестве доминирующего, и в какие отношения производства, распределения и потребления их родовых сущностных сил люди необходимо будут поставлены в процессе производства своей материальной жизни, т.е. как будет функционировать социетальная отрасль культуры.

Возвращаясь к уже затронутому нами вопросу об использовании свободного времени элитными слоями общества, заметим, что трата ими воплощенного в свободном капитале не ими произведенного свободного времени на неоправданную роскошь, примитивные наслаждения и бессмысленный сверхкомфорт обратной своей стороной является сокращением возможностей для современной цивилизации адекватно ответить на вызовы современности, тогда как отнимание минимально необходимого для свободного развития - это и есть минимизация вынужденной бесчеловечности. Изменение социальных отношений является условием реализации уже появившейся возможности продвижения к большей человечности, т.е. если свободного времени уже больше, чем было до этого, если распределив его иначе, нежели до этого, мы сможем обеспечить развитие для большего числа людей. Обеспечивая своими инновациями повышение уровня культурного развития, люди-креаторы содействуют накоплению потенциала ускоренного развития культуры, и тем самым делая возможным переход от наличного типа социальности к другому, в рамках которого только и возможна реализация накопленного потенциала развития. Необходимость же такого перехода создается не ими, она возникает в тех случаях, когда возникает опасность самого существования культурного сообщества. Таким образом, мы наблюдаем в истории единство прерывности развития социальной и непрерывности развития антропной культуры, проявляющиеся в скачкообразном изменении социальной формы этого развития, способов распределения культурных компетенций между людьми и самих людей между сферами и видами культурной деятельности. Это происходит в силу неизбежного нарушения меры между наличным уровнем культурного развития и его максимально достижимыми темпами.

Если же эти переходы рассмотреть со стороны их содержания, то они предстанут перед нами антропокультурными переворотами в развитии антропосоциокультурных тотальностей, в ходе которых радикально меняется способ развития, фрагментации, распределения и присвоения людьми исторически накопленного объема своего родового развития, который есть не что иное как социальность. В таких переходах не только меняется конфигурация моментов антопосоциокультурных тотальностей, но меняется также тип доминирующей человеческой личности и сменяется ведущая отрасль культуры, при том, что антропная культура всегда остаётся основной, материальная - определяющей, а социальная - результирующей. Духовная же культура является медиационной, опосредующей процессами осознания людьми объективно существующих возможностей и необходимостей в тех или иных культурных инновациях, превращение их в действительность, то есть сознательное их осуществление в той или иной из названных выше отраслях культуры. Непрерывно воспроизводимые и периодически развиваемые новые человеческие сущностные силы увеличивают объем культурного развития культурного сообщества. Будучи опредмеченными в материальной культуре в виде артефактов, важнейшие из которых приводят к повышению уровня культурного развития, что приводит к накоплению нового потенциала культурного развития, необходимость реализации которого активизирует развитие социальной отрасли культуры в виде инициирования новых социокультурных и социоантропных практик и соответствующих социальных институтов, призванных воплощать их в жизнь. Эти социокультурные инновации активизируют антропокультурные процессы и т.д. 
Описанные нами перевороты в социокультурной истории человечества принято называть социальными революциями, названные К. Марксом, «локомотивами истории». Предпринятое нами их концептуальное моделирование существенно ослабляет привычные аберрации понятия «социальная революция» как, прежде всего насильственные и в большинстве своем кровавые эксцессы, нарушающие «нормальное» эволюционное течение человеческой истории.

В результате предпринятой нами концептуализации базовых для понимания концепта социальности категорий «человек» и «культура» социальные революции представляются обязательным условием ускорения темпов развития человеческих сущностных сил в кризисные эпохи человеческой истории и, что самое главное, они меняют отношения производства, распределения и потребления прежде всего человеческих родовых сущностных сил, в соответствии прежде всего с уровнем их развития.

Опираясь на наши предыдущие исследования о человеке и культуре $[2 ; 3]$ и введя в нашу концептуальную модель такие моменты как объем, уровень и телпы культурного развития, мы пришли к выводу, что существенным индикатором уровня развитости культуры является уровень человечности в формирующемся человеке.

Социальность в полученной нами в качестве одного из значимых результатов нашего исследования концептуальной модели процесса эволюции атропосоциокультурной тотальности, будучи моментом как концепта «человек», так и концепта «культура», выступает общим для них результирующим моментом. В динамическом концепте «человек» характерный для того или иного этапа эволюции человеческого рода необходимо заданный уровень человечности развитого человека проявляется именно в естественном для него типе социальности. И в этом смысле исторически развитая сущность человека в ее действительности, есть не что иное как «совокупность всех общественных отношений” (К. Маркс) является показателем естественности протекающего процесса антропокультурогенеза, т.к. культура, человек, а следом и социальность - не что иное, как один из атрибутов современного этапа в эволюции биосферы, возникающий и протекающий по логике естественноисторической необходимости.

На протяжении всего исторического процесса человек, мог быть развитым, только будучи бесчеловечным по отношению к тем людям, за счет которых он развился, либо человечным и неразвитым по определению. То есть развитый человек не мог быть человечным в большей мере, чем того ему позволял уровень развития материальной культуры. На современном этапе развития человека, перед лицом глобальных проблем современности, человек снова оказывается перед необходимостью стать более человечным не только во имя собственного развития, но и для выживания.

Следовательно, повышение человечности в людях в ее уже положительной форме должно стать приоритетом в современной социальной инженерии, которая одна способна высвободить такие объемы креативности, которые позволят на основании познанных необходимостей космологической эволюции организовать процесс преобразования природы естественным, а не противоестественным для самой природы способом. Это значит, что, только став по-настоящему и в достаточной степени человечным, род человеческий способен стать тем, кем он необходимо должен быть, чтобы быть - органом самосознания и конструктивной самоорганизации Природы по логике естественноисторической необходимости.

Выводы. Основные результаты предпринятой нами в данной статье попытки окончательной концептуализации феноменов человека и культуры можно свести следующим положениям

1) Человек - это:

- самовоспроизводящий себя в процессе антропосоциокультурогенеза агент антропогенной эпохи эволюции природы;

- молярный носитель идеальных сетевых программ собственного аутопоэзиса;

- сформированный на атомарном материальном субстрате эволюционно возникшего достаточно высокоразвитого для этого биологического вида;

- в перманентно культивируемых им целенаправленных процессах результативной организации закономерно необходимых последовательностей актов;

- преднамеренно организуемого им целерационального взаимодействия актуальных элементов природной среды, непригодной в ее преднаходимом состоянии для существования в ней своего биологического субстрата;

- ведущих к превращению преобразуемых им элементов враждебной природной среды в конститутивные элементы искусственной среды обитания сообществ этих особого рода, социокультурных по своей природе существ;

- постепенно расширяющий фронт взаимодействия с «первой» природой, становясь в этом отношении все более и более универсальной природопреобразовательной силой, способной все полнее гарантировать выживание своего биологического субстрата;

- однако осуществляющий эту свою технологическую экспансию в область «первой природы» в направлении, противоположном направленности естественной эволюции и по этой причине вызывающий своей культурогенеративной активностью попутную неконтролируемую и порой необратимую деградаций «первой природы»; 
- остановить которую он может не иначе, как только став органом самосознания и конструктивной, природособразной организации природы, т.е., сформировать на базе биосферы и над ней сформировать ноосферу - сферу природосообразных процессов, организуемых по логике естественной эволюции.

Культура - это:

- закономерно зародившаяся вследствие длительной эволюции биосферы более высокая по отношению к этой последней форма рефлексивной самоорганизации природы и характеризующаяся объемом, уровнем и темпами своего развития,

- возникающая в форме вынужденного перехода достаточно высокоорганизованной для решения этой задачи формы жизни от сложнейшего изменения природы к ее простейшему преобразованию,

- состоящая их таких областей:

- антропной, культивирующей людей в качестве родовых существ, т. е. как носителей и агентов процесса антропогенеза - это базовая область культуры;

- материальной, культивирующей овеществленные в природном веществе системные результаты природопреобразующей активности человека в виде искусственной среды его обитания, образующей мир человека - это определяющая область культуры, от уровня развития которой зависит социальная конфигурация всей культуры и содержание производимых в каждой отрасли культурных ценностей;

- социальной, культивирующая посредством создаваемых в ней социальных институтов известные типы социальных отношений между людьми позиционируя их путем интериоризации взаимноскоординированных в системе совместно-разделенной деятельности сращений культурных компетентностей, важнейшей из которых является культурная креативность - результирующая отрасль;

- духовной, культивирующей идеальные программы процессов производства и самовоспроизводства всей системы артефактов, из природных предметов, природных веществ и природных сил по законам природы в целях непрерывного воспроизводства жизни в самой ее высокоразвитой форме - это медиационная область опосредующая превращение объективных природных и социальных необходимостей в сознательные действия людей.

- развертывающийся в историческом времени, ускоряющем свое течение по мере повышения уровня развития культуры

- долго протекала в противоестественных для природы формах, поскольку начиналась с экспансии гоминид в биосферу, потом в область химических, и затем в область физических явлений, в то время как эволюция природы протекала в прямо противоположном направлении - от физической эпохи к химической и далее - к биологической.

\section{Jumepamypa}

1. Белякова Е.А. Методологические основания, процедуры и пути концептуализации в социогуманитарной науке. Культурологічний вісник: науково-теоретичний щорічник Нижньої Наддніпрянщини / Гол. ред. М.А. Лепський; Запорізький національний університет. Запоріжжя: КСК-Альянс, 2019. Вип. 40. С. 22-30.

2. Бєлякова К.О. Логіка необхідності виникнення людини як логіка саморозгортання концепту «людина» (з історії в теорію). Культурологічний вісник: Науково-теоретичний щорічник Нижньої Наддніпрянщини. 2020. Вип. 41. Т. 1. С. 20-29. doi.org/10.26661/ 2413-2284-2020-1-41-02.

3. Белякова Е.А., Эль Гуэссаб К. Деконструкция понятия «культура». KELM (Knowledge, Education, Law, Management ). 2020. № 3(31). C. 27-34.

4. Борисов И.А., Козьмин Ф.Е. Изобретение гражданского общества в реформах Солона: полидисциплинарный анализ. Известия Лаборатории древних технологий. 2019. Т. 15, № 1. С. 113-122. DOI: http: // dx/doi/org/10.21285/2415-8739-2019-1-113-122.

5. Каган М.С. Философия культуры. СПб: Петрополис, 1996. 416c.

6. Кизима В.В. Бытие как тотальность. Современная философская картина и ее приложения. TotalogyXXI. Постнекласичні дослідження. 2012. № 27. С. 71-89. 7. Малыхин В.И. Катастрофы нового типа. Вестник Московского гос. юрид. университета. ил. О.Е. Кутафина. 2014. № 3. С. 143-146.

7. Манжура В.И. Антропосоциокультурная тотальность (АСК) - поверхность и глубина. Грани. 2006. № 3. С. $62-68$.

8. Манжура В.И. Быть ли человеку, не будучи доказательно мудрым? Грани. 2006. № 5. С. 44-50.

9. Мегрелидзе К.Р. Основные проблемы социологии мышления. Тбилиси: Мецниереба, 1973. 437 с.

10. Миронов А.В. Философия науки, техники и технологий. М.: МАКС Пресс, 2014. 272 с.

11. Московкин В.М. Доклад Римского клуба: оргии самокритики. Наука. Искусство. Культура. 2018. Вып. 2. С. 126-145.

12. Николенко К.В. Социальная роль креативности в современной культуре. Ученые записки Таврического национального университета ил. В.И. Вернадского. 2012. Т. 24, № 1-2. С. 178-183.

13. Подвойский Г.Л. Давос-2018: глобализация меняет лицо. Глобальный мир и внешняя политика России. 2018. № 3. С. 50-58. DOI: 10.26794/2226-78672018-8-3-50-58.

14. Рабинович И. Человечество: путь прогресса. 2018. URL: https: //libs.ru/book/542459/read (дата звернення: 22.12.2020)

15. Сабадаш Ю.С. Ауреліо Печчеї та «Римський клуб». Вісник Маріупольського державного університету. 2011. Вип. 1. С. 122-129.

16. Саітгареєва О.Г. «Економічна людина» в умовах глобалізації: соціально-філософський аналіз: автореф. дис. ... канд. філос. наук: 09.00.03/ запорізький національний університет. Запоріжжя, 2011. 20 с.

17. Сачкова Н.А. Инкультурация как культурологическая и педагогическая проблема. Педагогическая наука и практика. 2019. № 2 (24). С. 19-21. 
18. Сорокин П.А. Социальная и культурная динамика / пер. с англ., вступ. ст. и коммент. В.В. Сапова. М.: Астрель, 2006. 1176с.

19. Струмилин С.Г. Проблемы социализма и коммунизма в СССР. М. : Экономиздат, 1961. 415 с.

20. Цупренко 3.В. Життєздатність суспільства: соціально-філософський аналіз: автореф. дис. ... канд.. філос. наук: 09.00.03 / Запорізький національний університет. Запоріжжя, 2015. 16 с.

21. Янтуш О.А. Культурологическая теория образования: дис. ... д.ра культуролог. наук: 24.00.01. СПб: РГПИ им. А.И. Герцена, 2019. 261 с.

\section{Анотація}

Бєлякова К. О. Деконструкція бінарної опозиції категорій людини та культури як кінцевий етап їх концептуалізації. - Стаття.

У статті зроблена спроба завершити концептуалізацію феноменів людини і культури в якості протилежних моментів суперечливої основи феномена соціальності. Завданням статті є деконструкція бінарної опозиції «людина» - «культура» і перетворення їі в суперечливу основу тернарной композиції антропосоціокультурной тотальності.

Концептуалізація понять людини і культури є синтетичною науковою задачею і передбачає категоріальне відтворення процесу виникнення і безперервного перевиникнення найскладніших 3 усіх існуючих об'єктів, оскільки вони «знімають» в собі всі інші еволюційні процеси, що вивчаються космологією, еволюційної біологією укупі з палеонтологією і археологією, описовою та теоретичною соціогуманітаристикою, що включає етнографію, культурну та соціальну антропологію і соціологію культури. Завершуючи перелік наукових дисциплін, автор цього дослідження спирається на останні досягнення, теоретичної філософії з діалектикою, що історично сформувалася як загальна теорія розвитку, філософською антропологією, філософією історії та філософією культури. Виток традиції раціонального осмислення людини і культури лежить в античній філософії, що вважала людину не просто частиною, а аналогом Макрокосму (з чим охоче погоджується сучасна космологія з ї̈ антропним принципом). У антропоцентричній філософії Відродження ми знаходимо ідею незавершеності самотворення людини, і через століття цю думку Мірандолла по-своєму повторить Ніцше в своєму «Заратустрі». Думка просвітителя Гердера про необхідно зумовлену будовою Сонячної системи появу людини на одній з її планет перегукується з тейярдістскім уявленням про природу феномена людини і центральними ідеями т.зв. «Великої» або «Універсальної» історії. Ми не могли залишити без уваги зусилля не тільки класичної, але також некласичної і постнекласичної філософії, що деконструює бінарну опозицію класичних і некласичних підходів в тернарну композицію постнекласичної соціогуманітаристики.
Ключові слова: соціальність, антропосоціокультурогенез, бінарна опозиція, тернарна композиція, соціальна міра людяності, соціальна міра культурності, рівень, обсяг, темпи розвитку культури, спеціалізація, соціальна революція, соціальна рівність, соціальна нерівність, поділ праці, антропосоціокультурна тотальність.

\section{Summary}

Bieliakova K. O. Deconstruction of binary opposition of categories of man and culture as a final stage of their conceptualization. - Article.

The article attempts to complete the conceptualization of phenomena "human" and "culture" as opposing moments of the contradictory basis of the phenomenon of sociality. The aim of the article is to deconstruct the binary opposition "human" - "culture" and turn it into a contradictory basis for the ternary composition of anthroposociocultural totality.

The conceptualization of the concepts of human and culture is a synthetic scientific task and presupposes a categorial reproduction of the process of appearance and continuous reappearance of the most complex of all existing objects, since they "remove" all other evolutionary processes studied by cosmology, evolutionary biology, together with paleontology and archeology, descriptive and theoretical socio-humanities, including ethnography, cultural and social anthropology and sociology of culture. Completing the list of scientific disciplines, the author of this study relies on the latest achievements, theoretical philosophy with its historically formed dialectics as a general theory of development, philosophical anthropology, philosophy of history and philosophy of culture. The source of tradition of rational understanding of human and culture lies in ancient philosophy, which considered a human to be not just a part, but an analogue of the Macrocosm (with which modern cosmology readily with its anthropic principle agrees). In the anthropocentric philosophy of the Renaissance, we find the idea of the incompleteness of human self-creation, and through the centuries this idea of Mirandolla will be repeated by Nietzsche in his "Zarathustra". The idea of enlightener Herder about the necessary appearance of human on one of the planets due to the structure of the Solar system, echoes the Teilhardist concept of the human essence and the central ideas of the so-called. "Big" or "Universal" History. We could not ignore the efforts of not only classical, but also non-classical and post-non-classical philosophy, which deconstructs the binary opposition of classical and non-classical approaches into the ternary composition of post-non-classical socio-humanities.

Key words: sociality, anthroposociocultural genesis, binary opposition, ternary composition, social limit of humanity, social limit of culture, level, volume and rates of cultural development, specialization, social revolution, social equality, social inequality, division of labour, anthroposociocultural totality. 